\title{
Immune Alterations in IgE and Non IgE-Associated Atopic Dermatitis
}

\author{
Giampaolo Ricci*, Elisabetta Calamelli and Francesca Cipriani
}

Pediatric Unit, Department of Medical and Surgical Sciences, S. Orsola - Malpighi Hospital, University of Bologna, Bologna, Italy

\begin{abstract}
Atopic dermatitis is a complex disease in which a strong interaction between alterations of skin barrier and the adaptive immune system coexists. In the recent years, new findings have underlined the importance of skin proteins, especially filaggrin, which participate to the outmost layers of the skin. To strengthen this physical barrier, many factors are available, such as antimicrobial peptides, chemokines and cytokines produced by keratinocytes. Skin disruption can easily allow the allergen penetration and the local keratinocytes can promote the adaptive immune response toward a Th2 phenotype. On the other side, allergic Th2 cytokines may downregulate the production of skin barrier proteins, facilitating the penetration of allergens. Moreover, data on murine models show the absolute relevance of the systemic immune system to develop clinical skin reaction. Since the clinical aspect of patients with AD does not show different patterns whatever is the prevalent underlying mechanism, in clinical practice it is difficult to translate the different endotypes beside the IgE and non IgE associated forms. The aim of this review is to point out to the most recent knowledge in this field, which makes AD more difficult to frame in a unique clinical entity.
\end{abstract}

Keywords: Atopic dermatitis, endotype, filaggrin, IgE, immune system, skin barrier, Th2.

\section{INTRODUCTION}

In 1970, few years after the discovery of $\operatorname{IgE}(1966)$, Johansson et al. published a paper where, describing the spectrum of diseases with high IgE levels, indicated among these atopic eczema and classified it into two subgroups: atopicum eczema (frequently with high IgE) and nonatopicum eczema (a skin disease with the same features skin lesions and their distribution pattern- but without evidence of $\operatorname{IgE}$ sensitization to aero- or food allergens) [1]. This was the first observation in which a difference in atopic eczema was underlined after the discovery of IgE. Indeed, in 1933, Wise and Sulzberger had already proposed the definition of "atopic dermatitis" (AD) to emphasize its close association with other atopic diseases, especially allergic rhino-conjunctivitis and asthma [2]. The possible link with the immune system and allergic diseases stimulated numerous studies to investigate the underlying pathogenic mechanisms.

\section{THE FIRST IMMUNOLOGICAL STUDIES}

In the course of the years, the immunological studies on $\mathrm{AD}$ followed the progressive update knowledge: among the earlier ones is paradigmatic the work published in 1975 by the group guided by Rebecca Buckley, that described an alteration of cell-mediated immunity in inverse relationship with the level of total IgE, detected analyzing peripheral white cells of subjects with atopic eczema [3]. Thus far, in these initial studies lymphocytes were differentiated into two

*Address correspondence to this author at the Pediatric Unit, Department of Medical and Surgical Sciences, S. Orsola- Malpighi Hospital - University of Bologna, Via Massarenti, 9, 40138 Bologna, Italy; Tel: +39 051636 3075; Fax: +39 051636 3075; E-mail : giampaolo.ricci@unibo.it main sub-groups through the formation of rosettes E. However, these researches strongly reflected on the clinical level: in 1978 the Lancet published a double-blind trial conducted by the Institute of Child Health in London [4]. In this study, authors highlighted the advantages of an exclusion diet in children suffering from $\mathrm{AD}$ with more severe clinical features; these data have been later confirmed by further observations. These studies lead to profound changes in clinical practice: from this time the elimination diet had a stronger impact on the therapeutic strategies of paediatricians.

In order to better define the disease, clinician tried to separate the two distinct forms of $\mathrm{AD}$ : one characterized by the presence of high $\operatorname{IgE}$ and associated allergic manifestations (also named "extrinsic AD") and the other one with normal IgE without allergic symptoms (or "intrinsic AD"), with a high prevalence of the former type but different percentage in relation to age and severity of the disease (Table 1) [5-16].

In the meantime, the immunological network incredibly complicated: with the advent of monoclonal antibodies an important step in the knowledge of the immune system had been made. It was possible to distinguish different subtypes of lymphocytes with different functions; this allowed much more accurate results to be obtained, and moved the target organ from the blood to the skin.

In 1981 the first data on $\mathrm{T}$ cell subsets using monoclonal antibodies in $\mathrm{AD}$ patients appeared: Leung et al. reported data about in vitro cellular reactivity from 22 patients with $\mathrm{AD}$ by using monoclonal antibodies to recognize different peripheral lymphocytes [17]. Patients with AD showed a lower rate of $\mathrm{T} 3+$ cells (now named $\mathrm{CD} 3+$ ) and $\mathrm{T} 8+$ cells (now named $\mathrm{CD} 8+$ ) but not of $\mathrm{T} 4+$ (now named $\mathrm{CD} 4+$ ) 
Table 1. Prevalence of non IgE-associated type atopic dermatitis (AD) in different studies.

\begin{tabular}{|c|c|c|c|}
\hline Reference & No. of Patients & Pts with Non IgE-Associated AD, n (\%) & Age (Years) \\
\hline \hline Wüthrich et al. $1990[5]$ & 37 & $9(24 \%)$ & $14-60$ \\
\hline Hochreutener $1991[6]$ & 40 & $5(30 \%)$ & $1-7$ \\
\hline Walker et al. $1993[7]$ & 25 & $14(42 \%)$ & $19-55$ \\
\hline Kägi et al. $1994[8]$ & 33 & $27(45 \%)$ & $0-12$ \\
\hline Cabon et al. $1996[9]$ & 59 & $17(18 \%)$ & 37 \\
\hline Wüthrich $1999[10]$ & 93 & $726(25 \%)$ & $5-14$ \\
\hline Schäfer et al. $1999[11]$ & 2201 & $8(11 \%)$ & 36 \\
\hline Fabrizi et al. $1999[12]$ & 72 & $117(10 \%)$ & $11-51$ \\
\hline Akdis et al. $1999[13]$ & 1151 & $93(27 \%)$ & $1-24$ \\
\hline Laske \& Niggemann $2004[14]$ & 345 & $764(35 \%)$ & $1-2$ \\
\hline de Benedictis et al. $[15]$ & 2184 & $15(8 \%)$ & $8-18$ \\
\hline Ricci et al. $2014[16]$ & 184 & & \\
\hline
\end{tabular}

compared to controls. An interesting finding was the higher $\mathrm{T} 4+/ \mathrm{T} 8+$ ratio observed in 17 of 22 patients with atopic dermatitis but not in the control subjects.

The main characteristics that suggested an immune pathogenesis in AD were summarized by Donald Leung in 1995 as listed below: increased IgE levels, skin test sensitization to multiple allergens, higher spontaneous histamine release by basophils, lower number of CD8 suppressor/cytotoxic lymphocytes with less effective function, higher expression on mononuclear cells surface of the low-affinity receptor for IgE CD23, increased rate of Th2-like cells secreting IL-4 and IL-5, and decreased rate of numbers of those ones secreting IFN- $\gamma$ with a significant inverse correlation between in vitro IFN- $\gamma$ production and in vivo IgE serum concentrations in AD patients [18]. Furthermore, other studies confirmed the increased number of T cells producing Th2-like cytokines such as IL-4, IL-5 and IL-13 in response to specific allergens, but decreased number of $\mathrm{T}$ cells producing IFN- $\gamma$ in peripheral blood samples of patients with $\mathrm{AD}[19,20]$.

At the same time the immunological studies were also directed to the comprehension of skin function; it was found that the skin cells were able to recognize antigens and to elicit a systemic immune response. Spergel et al. [21] described the mechanism of epicutaneous sensitization in a murine model: the induction of allergic sensitization by ovalbumin, a well known allergenic protein, leads to an increase in levels of total and ovalbumin-specific serum $\operatorname{IgE}$ and to the development of the atopic dermatitis skin lesions, with a local appreciable infiltrate of $\mathrm{CD} 3+\mathrm{T}$ cells, eosinophils and neutrophils, and expression of IL-4, IL-5 and INF- $\gamma$ mRNA. These cutaneous immunohistological features corresponded to the Th2 response (increased IL-4, IL-5, and IL-13 levels) of the acute phase of AD, while chronic lesions showed meanly a prevalence of Th1-cytokines (IL-12 and IFN- $\gamma$ ). The two types of AD did not show dramatic differences in the expression of inflammatory cytokines: IL5 and IFN- $\gamma$ were detectable in similar amounts, while IL-4 and IL-13 showed a lower expression in non IgE AD, especially in the lesional skin.

\section{THE ADVENT OF GENETIC STUDIES}

The new advance on basic science is promptly reflected on clinical research: with the advent of the new technologies of gene analysis, the skin barrier became the protagonist. In 2002, Coxson and Moffatt [22] understood that a gene or a cluster of genes, coding for proteins involved in the formation of the deep layers of the skin, may play a key role in the pathogenetic mechanisms of atopic dermatitis, including allergic sensitization. But only in 2006 data from a cohort of Irish patients with AD were published in Nature Genetics [23]: authors found alterations in the nucleotidic sequence of the gene encoding for filaggrin. This protein is the most important among those of the so called "epidermal differentiation complex" and is fundamental to preserve the skin barrier integrity. Moreover, filaggrin is able to promote the aggregation of the keratin filaments and its functional defects have described as a risk factor for the onset of AD. Furthermore, in subjects with AD two variants of this gene (R510X and 2282del4) were associated with the occurrence of allergic asthma. Otherwise, these alterations of the gene of filaggrin were observed in not more than $30 \%$ of patients, so that was insufficient to explain the pathogenesis of AD. Later, further studies on additional proteins that might contribute to the integrity of the skin barrier had been performed, and other skin proteins (e.g. loricrin, claudine 1) have been associated to the development of $\operatorname{AD}[24,25]$.

\section{THE IMMUNE RESPONSE: WHAT WE KNOW NOW}

The contribution of multiple cell types, and the existence of multiple cytokine patterns at different evolution stages give an idea of the high complexity of the mechanisms involved in the immune response in patients with AD.

\section{The Skin Immune Response}

A model to study the immune response is to analyze the cellular skin infiltrate after atopy patch test (APT) to house dust mites (HDM). Epicutaneous application of HDM frequently induces eczema in the nonlesional skin of $40-50 \%$ of patients with AD. By using immunohistochemistry and molecular analysis, it has been shown that also cytotoxic $\mathrm{T}$ 
cells are implicated in the pathogenesis of these lesions; the analyses from a murin model showed that very few CD8+ T cells infiltrating the skin (about 5\% among the CD45+ cells) are sufficient to trigger the HDM-induced AD lesions and their presence is even indispensable, because mice depletion with anti-CD8 monoclonal Abs completely suppressed the inflammatory process [26]. In a recent study, patients with mild to moderate $\mathrm{AD}$ were enrolled on the basis of the positivity of APT to HDM; in nine patients the skin biopsy showed that CD8+ T cells are involved in the early phase of the response to allergen exposure. A hypothesis is that the apoptosis of keratinocytes and the epidermal spongiosis, which are both pathological hallmarks of $\mathrm{AD}$, are due to the cytotoxic activity of CD8+ cells [26].

Recently, in vivo studies evidenced new relevant details in the skin immune response. In certain allergic tissue reactions potent agents with vasodilator and permeability functions were recognized to be expressed by the inflammatory cells in the lesional skin, such as the calcitonin gene-related peptide (CGRP) and the vascular endothelial growth factor (VEGF). Skin biopsy specimens from atopic dermatitis lesions were collected after various times from the cutaneous allergen exposure and analysed by using single and double immunohistochemistry and in situ hybridization: neutrophils and $\mathrm{CD}^{+}{ }^{+} \mathrm{T}$ lymphocytes were the main $\mathrm{CGRP}^{+}$ cells detected at the late-phase of the reaction (i.e., 6 hours) [27]. In the setting of allergic inflammation, the wide CGRP production by neutrophils may clarify the characteristic vasodilation that can be observed in the late-phase of the skin reaction: thus it could be at least in part a neutrophildependent phenomenon [27]. Otherwise, in patients with chronic $\mathrm{AD}$ and in those with psoriasis, the lesional skin biopsy specimens show that dendritic cells (DC) did not increase a preferential $\mathrm{T}$-cell subsets in a disease-specific manner. The capacity of each DC subset to increase Th1, Th2, Th17 and Th22 subsets was the same in the two diseases, but an upregulation of specific chemokine expression such as CCL17, CCL18, and CCL22 was observed only in patients with AD [28]. Moreover, in patients with $\mathrm{AD}$, cutaneous biopsy showed an impaired IFN- $\gamma$-mediated signaling pathway and a decreased IFN- $\gamma$ production both in DCs and in their precursor cells; this condition might contribute to the Th2 bias [29]. On the other side, the increased IFN- $\gamma$ responses suggest the role of multiple new factors involved in the mechanisms of apoptosis and inflammation in the development of $\mathrm{AD}$ [30]. Also other mediators, such as TNF- $\alpha$ and the TNF-like weak inducer of apoptosis (TWEAK), cooperate in the induction of keratinocyte apoptosis and in the lesional production in $\mathrm{AD}$ patients [31]. Indeed, during disseminated viral infections such as eczema herpeticum, which is caused by herpes simplex virus, patients suffering from AD showed a mixture of defects both in the skin barrier function and in the innate and adaptive immune responses. In particular, an impaired IFN- $\gamma$ response was observed in human $\mathrm{AD}$ complicated by eczema herpeticum: indeed genetic variants as single nucleotide polymorphisms were found in IFN- $\gamma$ and IFNGR1 genes and they were significantly related with eczema herpeticum and abnormal IFN- $\gamma$ production [32].

Also mutations of STAT6 (signal transducer and activator of transcription 6) gene increase make patients with $\mathrm{AD}$ more prone towards disseminated viral skin infections
[33]. Also the cellular transcription factor Specificity protein $(\mathrm{Sp})-1$ is involved in diverse cellular functions and represents a critical player during the antiviral responses of skin keratinocytes. Sp1 deficiency in AD patients with viral infection may contribute to increase the risk to develop a disseminated infection of the skin [34].

Recently, the molecular and cellular pathogenetic mechanisms of lesional and nonlesional AD (intrinsic and extrinsic) have been studied in 51 patients with severe AD by using the gene expression assay (real-time PCR). While a prominent infiltrate of $\mathrm{T}$ cells and DCs was observed in lesional skin of both types of $\mathrm{AD}$, patients with the intrinsic form $(\mathrm{n}=9)$ showed a Th17 immune response more increased than those with extrinsic AD $(n=42)$ [35]. Moreover, higher activation of all inflammatory axes, with a particular involvement of Th17 and Th22 cytokines, including the Th2 products, was detected in patients with intrinsic AD. A positive association between Th17-related molecules and severity of AD, assessed by SCORAD index, was found only in patients with intrinsic $\mathrm{AD}$, whereas patients with extrinsic AD showed a characteristic positive association between the SCORAD index and Th2 cytokine levels (IL-4 and IL-5) and inverse association with proteins involved in the skin differentiation (e.g. loricrin and periplakin) [35].

\section{AGAINST THE BIPHASIC MODEL}

The current model to describe the skin inflammation in AD largely descends from experimental studies performed by using APTs with environmental allergens to induce acute lesions and simulate the acute phase of the disease $[36,37]$.

As previously described, $\mathrm{AD}$ pathogenesis is characterized as a biphasic $\mathrm{T}$ cell-mediated disease: an early Th2 pattern which predominates in the acute phase and a late Th1 pattern which prevails in the chronic phase [36, 37]. On the basis of an experimental model comparing spontaneous acute $\mathrm{AD}$ lesions with chronic lesions from the same patient should permit the develop of a new viewpoint [38]. This new perspective to explore this mechanism was recently performed: biopsy specimens from acute lesion, chronic lesion ( $>72$ hours duration), and nonlesional skin and blood samples from the same patient were collected from 17 patients with moderate-to-severe AD. A significant increases in gene expression levels of Th2 (i.e. IL-4, IL-13, and IL-31) and Th22 (i.e. IL-22) cytokines was associated with the onset of acute lesions; the quantitative gene expression showed also a raise of some other inflammation products as IL-31, IL-22, S100A7, S100A8, and S100A9 with a positive correlation between the SCORAD index and IL-22 mRNA expression [38]. Th1 products induced by interferon, in particular IFN- $\gamma$, was also decreased in acute skin lesions. A small increase of Th17-cytokines were observed in acute disease associated with a higher increase in IL17-regulated products (CCL20, peptidase inhibitor 3 elafin, and lipocalin 2). Instead IL-22 mRNA and its associated products (S100A7, S100A8, S100A9, and IL-32) showed a progressive increase and were detected both in acute and in chronic lesions [39]. The chronic phase is also characterized by an intensified release of Th2-related cytokines with the exception of IL-4; indeed a decrease of IL-4 levels has been observed from acute to chronic lesions [38]. The result of skin inflammation is a marked activation of the gene cluster codifying for proteins of the Epidermal differentiation 
complex and located on chromosome 1q, with an increased expression of S100A7, S100A8 and S100A9 genes. The hyperexpression of these genes induces a rapid increase in the synthesis of S100 proteins by epidermal keratinocytes both in acute and in chronic AD skin lesions. The S100A7, S100A8, and S100A9 proteins play important roles in the inflammation process, such as stimulation of $\mathrm{T}$ cells, monocytes, and neutrophils chemotaxis, as well as an action as a proinflammatory mediators in patients with multiple inflammatory diseases [40-43].

\section{Innate Immune System}

In the skin innate immunity is expressed through different cells and functional proteins. The first observation demonstrated a higher and massive recruitment of eosinophils into the skin in $\mathrm{AD}$ than in healthy individuals with a long-lasting eosinophil survival [44, 45]. Eosinophils' function is mainly as effector cells, but they may also play a role in immunoregulation mechanism, by promoting the cytokine switch from a Th2- pattern in acute lesions to a prevalent Th1-like pattern in the chronic stage of the disease $[46,47]$. The number of eosinophils in peripheral blood is elevated in both $\operatorname{IgE}$ and non IgE associated forms $[8,48]$.

Recent observations demonstrated the relevance of the local defences, in which antimicrobial peptides (AMPs) are essential in the clearance of microbial pathogens and in maintaining epidermal barrier efficiency [49]. AMPs include different proteins: in addition to the $\beta$-defensin family (HBD1, 2 and 3) and LL-37 (cathelicidin), other proteins show antimicrobial activity such as S100 family proteins and ribonuclease. AMPs are mainly synthesized in the stratum granulosum, incorporated into lamellar bodies, and then discharged into the stratum corneum.

Furthermore, it has been shown a reduction of LL-37, HBD2 and HBD3 levels in the epidermis of lesional skin of patients with $\mathrm{AD}$ if compared to those affected by psoriasis $[50,51]$, but an increase of these levels when comparing with nonatopic healthy controls [51].

The deficiency of cathelicidin confers to patients with $\mathrm{AD}$ a higher susceptibility towards viral infections. Although evidences from murine model of cathelicidin-deficient mice showed an increased viral replication in the site of inoculation, they did not develop disseminated skin viral infection [52]. This observation suggests that the mechanism underlying cathelicidin deficiency is insufficient alone to explain the etiopathology of disseminated viral infections and other immunological alterations should be involved in patients with eczema herpeticum. The action of cathelicidin seems to be different but complementary to the mechanism of action of IFN: indeed while cathelicidin acts extracellularly by damaging the viral envelope, IFN inhibits the intracellular viral transcription and translation [53]. Therefore in patients with AD both intracellular and extracellular defects in the antiviral response of the host are involved in increasing the susceptibility to viral infections.

Keratinocytes can modulate the release of inflammatory mediators (e.g., cytokines, chemokines, and AMPs) through the expression of specific receptors for the effectors of the innate immune response overall defined pattern recognition receptors (PRRs). The relation between $\mathrm{AD}$ and the innate immune receptors system has been clearly reviewed by Kuo et al., who remarked their synergic action in the production of pro-Th2 cytokines, as the Thymic Stromal Lymphopoietin (TSLP), IL-25 and IL-33, which drive the immune response towards a Th2 pattern [54].

TSLP is preferentially produced by epithelial cells such as keratinocytes and mucosal cells of the airway; the TSLP expression level is increased in the epidermal layers of $\mathrm{AD}$ patients if compared with healthy subjects and it shows a correlation with SCORAD index, in particular with the dry skin score [55].

In 10 adult patients with mild to moderate $\mathrm{AD}$, it was observed that the epicutaneous application of HDM using the APTs promotes the induction of TSLP and of CCL17/ Thymus and activation-regulated chemokine (TARC), as a potential indicators of TSLP bioactivity $[56,57]$.

\section{ADAPTIVE IMMUNE SYSTEM}

After the review article by Leung et al. issued in 1995 [18], an intriguing paper by Akdis et al. was published in 1999 [13]. The authors investigated the immunologic mechanisms among 1151 chronic AD patients $(10 \%$ of them with non- IgE associated $A D$ ) and they found that skin $T$ cells were always implicated in both the subtypes of $A D$, responding to staphylococcal enterotoxin $\mathrm{B}$, superantigens and cytokines (IL-2, IL-5, IL-13 and INF $\gamma$ ). Interestingly, skin $\mathrm{T}$ cells from non-IgE associated form expressed lower IL-13 and IL-5, while IL-4 was not found in any of the two types. Moreover, authors found a relevant expression of CD23 in the activated B cells of patients with IgE associated $\mathrm{AD}$, while the non-IgE associated form was mainly characterized by the absence IL-13-induced-B cells and subsequent IgE secretion.

Recently, new lymphocytes' phenotypes and cytokines have been identified. Th2 2 cells, originally identified as circulating T-cell clones with skin-homing properties, express receptors for chemokines (CLA, CCR4, CCR6 and CCR10.7) and do not coproduce IL-17, IL-4, or IFN $\gamma$. In thirteen patients with severe chronic $\mathrm{AD}$ a raised rate of $\mathrm{T}$ cells characterized by skin-homing capability and expressing both IL-13 and IL-22 was found. Indeed, this peculiar subtype of T-cells named "IL-13/IL-22-coproducing T cells" might act a potential key role in the pathogenesis of the disease [58].

Furthermore, not only Th2 cells have been identified as producers of IL-31, since also DCs, monocytes and mast cells are implicated in IL-31 synthesis: these cells have been isolated in the skin of subjects affected by $\mathrm{AD}$ and the expression of IL-31 was found to be raised also in the sera of these patients with a strong correlation with the grade of severity of the disease [59]. In addition, IL-31 plays a relevant role also in the process of skin differentiation: in a human 3-dimensional skin model filaggrin was observed to be downstream regulated by IL-31 [59].

Also the role of IL-10 is crucial in modulating the adaptive immune system: IL-10 owns suppressive properties both on DCs' maturation and subsequent cytokines expression, and on Th1 cell differentiation. Simultaneously, it contains properties of effector T-cells and enhances the function of Tregs, suggesting that the interaction between the different cell subsets (DCs, Tregs and effector T cells) is crucial in down-regulating 
an unbalanced activation of the immune system [60]. Studies on IL-10-deficient (IL-10 ${ }^{-1}$ ) mice have shown that DC-specific IL$10 \mathrm{R}^{-/}$rodents have an intensified hypersensitivity reactions towards contact haptens, arguing that the pathway of IL-10 signalling is crucial in limiting the contact hypersensitivity reaction, while it is not essential in T-cell priming [61]. In the end, IL-10, suppressing the expression of proinflammatory cytokines from monocytes and macrophages, plays also a critical role in modulating the responses of both the adaptive and innate immune systems [60, 61].

Also the interactions between the endocrine and the immune systems play an influent role in $\mathrm{AD}$ [62]: levels of corticotropinreleasing hormone $(\mathrm{CRH})$ receptor expressed by $\mathrm{T}$ cells were significantly lower in subjects with $\mathrm{AD}$ compared to controls. In contrast, in the healthy population, $\mathrm{CRH}$ induces the upregulation of IL-4 by Th2 cells and the inhibition of Th1 cells-induced IFN- $\gamma$ secretion. In subjects with $\mathrm{AD}, \mathrm{T}$ cells were not shown to secrete IL-4 and IFN- $\gamma$ after CRH treatment, while CRH significantly inhibits the synthesis of IL-10 from Tregs, giving an explanation to the stress-induced recurrences of $\mathrm{AD}$ skin lesions [62].

The relation between immune system and the development of $\mathrm{AD}$ skin lesions has been distinctly observed in a murine model showing the importance of the adaptive immunity in the spontaneous appearance of skin lesions. Filaggrin-deficient flaky tail (ft) mice $(F l g f t / f t)$ show spontaneous skin inflammation that imitates human AD. The breeding of Flgft/ft with Balb/c Rag2-deficient (Rag2-/-) generated mice with a lack of function of filaggrin as well as of $\mathrm{T}$ and $\mathrm{B}$ lymphocytes (Rag2-/-/Flgft/ft) [63]: these Rag2-/-/Flgft/ft mice didn't develop skin lesions during the observation period of 32 weeks, confirming that $\mathrm{T}$ cells and the adaptive immune system give an essential contribution to the development of skin inflammation [63].

A link between cytokines and $\mathrm{AD}$ has been shown by recent results from genome-wide association studies [64]. Data were obtained from a public repository about independent populations from two birth cohorts from the United Kingdom
(ALSPAC, 12 set 7) and Germany (Multicenter Allergy Study [MAS]): a significant association was detected for 318 genetic markers related to the expression of pro-inflammatory genes, identifying novel genetic risk factors for AD. A mutation in the amino acidic sequence of the IL-6 receptor (IL-6R Asp358Ala; rs2228145) resulting in a functional change of the protein, has been significantly associated with $\mathrm{AD}$, in particular with the persistent forms [64].

\section{THE INTERACTIONS AMONG SKIN IMMUNE RESPONSE AND THE INNATE AND ADAPTIVE IMMUNE SYSTEM}

The interplay among skin barrier and the innate and adaptive immune system in $\mathrm{AD}$ has been clearly summarized in recent review articles $[65,66]$. When the barrier function is compromised, haptens and protein antigens easily penetrate in the skin, promoting the switch toward a Th2cytokine pattern. Th2 (IL-4, IL-13, and IL-31) and Th22 (IL22) cytokines act as suppressors of the major final differentiation of skin proteins in keratinocytes (i.e., filaggrin and loricrin), enhancing the barrier disruption [35, 38,63]. Moreover, IL-4 and IL-13 have inhibitors capacity on the production of AMPs, directly inhibiting the expression of HBD-2 and HBD-3 and, indirectly, of hBD-3 and LL-37 (via inhibition of STAT6 activation) and subsequently suppression of TNF- $\alpha / \mathrm{NF}-\kappa \mathrm{B}$ and IFN- $\gamma$ production. On the other hand, IL-17 and IL-22 cytokines, derived from the recently identified T-cell subsets, have many effects on epidermal keratinocytes, enhancing the production of proinflammatory mediators such as S100A7, S100A8, and S100A9 proteins. In addition, keratinocytes by themselves release cytokines, chemokines and AMPs, which enhance the production of pro-Th2 cytokines, including TSLP, IL-25, and IL-33, and drive the immune response to surface antigens toward a Th2 profile. Finally TSLP stimulate DCs and induces the expression of cell-surface activation markers to promote Th2-skewed inflammatory responses (Table $\mathbf{2}$ ).

Table 2. Major interactions between skin barrier/innate immunity and adaptive immunity in AD patients.

Main Links Between Innate and Adaptive Immunity in AD

1. Eosinophils act as immunoregulatory cells, playing a role in the switch from a Th2-cytokine pattern in acute lesions of AD to a more Th1-like pattern in the chronic stage

2. TSLP (secreted by keratinocytes) stimulate DCs and induces the expression of cell-surface activation markers to promote Th2-skewed inflammatory responses

3. Keratinocytes release cytokines, chemokines and AMPs, which acts producing pro-Th2 cytokines, including TSLP, IL-25, and IL-33, and drive the immune response to surface antigens toward a Th2 profile.

Main Links Between Adaptive Immunity and Skin Barrier/Innate Immunity in AD

1. IL-4, IL-13 cytokines have inhibitors capacity on epidermal differentiation and production of antimicrobial peptides; they could inhibit the expression of hBD-2 and hBD-3 and might indirectly inhibit hBD-3 and LL-37 via inhibition of STAT6 activation and subsequently inhibit TNF-a/NF-KB and IFN- $\gamma$ production

2. IL-17 and IL-22 cytokines derived from the recently identified T-cell subsets have many effects on epidermal keratinocytes, S100A7, S100A8, and S100A9 mRNAs (human keratinocytes).

3. $\mathbf{T}_{\mathbf{H}} \mathbf{2}$ (IL-4, IL-13, and IL-31) and $\mathbf{T}_{\mathbf{H}} \mathbf{2 2}$ (IL-22) cytokines were shown to suppress the major final differentiation proteins (i.e., filaggrin and loricrin)

DCs: dendritic cells; TSLP: thymic stromal lymphopoietin. 


\section{FROM THE OLD NOMENCLATURE TO THE "UNIFYING HYPOTHESIS"}

In the last years the nomenclature and classification of $\mathrm{AD}$ has been revised: initially $\mathrm{AD}$ was classified in two subtypes named "extrinsic" (associated with atopic sensitization) and "intrinsic". The intrinsic type was not associated with specific IgE sensitization and with any of the clinical manifestation of other atopic diseases and was characterized by normal levels of total serum IgE. Later, the nomenclature changed and the current classification called the extrinsic form as "IgE-associated" and the intrinsic one as "non-IgE-associated AD" [67, 68]. However, a recently proposed model unified these two subtypes, considering them as different stages of the same pathogenetic process: indeed, while in the early infancy the non-IgE associated form is predominant, at a later stage the allergic sensitization occurs in most of the patients determining the switch to the IgE-associated phase [69-71].

\section{CONCLUSION}

$\mathrm{AD}$ is a complex disease in which many actors contribute to develop the clinical phenotypes. Nevertheless, many of these are not directly bound to the pathogenetic mechanism implicated: the two main actors are the primitive skin barrier defects (in particular the alterations of the filaggrin gene) and the immune system Th2-directed (i.e. cells, cytokines and chemokines allergic-oriented). The primitive barrier defect facilitates the passage of allergens and antigens; this contact actives innate immunity to develop a Th2 oriented response. On the other hand, allergic Th2 cytokines may downregulate the production of barrier proteins facilitating the income of allergens. These two main alterations may interact with different proportion each other (Fig. 1) determining many potential distinct endotypes, even if the phenotypic appearance of the skin shows similar characteristics in both pathways.

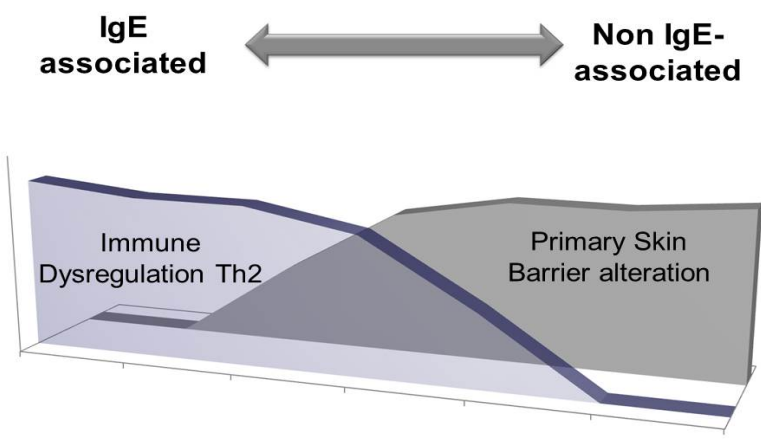

Fig. (1). Schematic representation of the two main alterations implicated in the development of the $\operatorname{IgE}$ and non $\operatorname{IgE}$ associated forms of atopic dermatitis. Both the primitive skin barrier defects and the immune dysregulation of Th2 system may interact the one with the other in different proportions, determining many potential distinct endotypes. On the one hand, the primitive barrier defect facilitates the passage of allergens and antigens and stimulate the innate immunity to develop a Th2-oriented response. On the other hand, allergic Th2 cytokines down-regulate the production of barrier proteins and facilitate the income of allergens.
It is difficult to translate in clinical practice such complex pathogenesis: the majority of patients (about $80 \%$ ) have an "IgE-associated AD", as recently suggested to be defined by Thomas Bieber [71]. Some patients, with the "non-IgE associated" form, seem to show an immune alteration profile only at the skin level, where together with the increase of IL5 and IL13, a wider production of IL17 appears to be stimulated, supporting the hypothesis of a link with an autoimmune course. Since skin disruption can easily allow allergen penetration and the local keratinocytes can promote an allergic immune response, the clinical intervention should be addressed to the strict control of the skin inflammation by the application of emollients with antinflammatory and proactive properties in order to interrupt this mechanism. On the other hand, a wider effort should be addressed to evaluate which is the allergic sensitization pattern of the patient, in particular during the paediatric age, since at this stage preventive strategies are still possible and effective. Meanwhile, how much the sensitization directly influences the course of $\mathrm{AD}$ should be determined by the physician on the basis of the clinical severity of the diseases and on the results of the allergic response.

\section{ABBREVIATIONS}

$\begin{array}{ll}\text { AD } & =\text { Atopic dermatitis } \\ \text { AMPs } & =\text { Antimicrobial peptides } \\ \text { APT } & =\text { Atopy patch test } \\ \text { CGRP } & =\text { Calcitonin gene-related peptide } \\ \text { CRH } & =\text { Corticotropin-releasing hormone } \\ \text { DC } & =\text { Dendritic cell } \\ \text { HBD } & \text {-defensin } \\ \text { HDM } & =\text { House dust mites } \\ \text { PRRs } & =\text { Pattern recognition receptors } \\ \text { Sp-1 } & \text { Specificity protein-1 } \\ \text { STAT6 } & =\text { Signal transducer and activator of transcription } \\ \text { TSLP } & =\text { ghene } \\ \text { TWEAK } & =\text { TNF-like weak inducer of apoptosis } \\ \text { VEGF } & =\text { Vascular endothelial growth factor }\end{array}$

\section{CONFLICT OF INTEREST}

The authors confirm that they have no conflict of interest.

\section{ACKNOWLEDGEMENTS}

Declared none.

\section{REFERENCES}

[1] Johansson SG, Bennich H, Berg T, Högman C. Some factors influencing the serum $\operatorname{IgE}$ levels in atopic diseases. Clin Exp Immunol 1970; 6: 43-7.

[2] Wise F, Sulzberger MB. Footnote on the problem of eczema. Neurodermatitis and lichenification. In: Wise F, Sulzberger MB, Eds. The 1933 year book of dermatology and syphilology: Chicago, Year Book Publishers 1933; 38-9.

[3] McGeady SJ, Buckley RH. Depression of cell-mediated immunity in atopic eczema. J Allergy Clin Immunol 1975; 56: 393-406. 
[4] Atherton DJ, Sewell M, Soothill JF, Wells RS, Chilvers CE. A double-blind controlled crossover trial of an antigen-avoidance diet in atopic eczema. Lancet 1978; 25: 401-3.

[5] Wutrich B, Joller-Jemelka H, Helfenstein U, Grop PJ. Levels of soluble interleukin-2 receptors correlate with the severity of atopic dermatitis. Dermatologica 1990; 181: 92-7.

[6] Hochreutener H. Clinical aspects and allergy-immunologic parameters in 40 children $0-7$ years of age with atopic dermatitis [Klinische Aspekte und allergologisch-immunologische parameter bei 40 Kindern von 0-7 Jahren mit atopischer Dermatitis]. Monatsschr Kinderheilkd 1991; 139: 618-25.

[7] Walker C, Kagi MK, Ingold P, et al. Atopic dermatitis: correlation of peripheral blood $\mathrm{T}$ cell activation, eosinophilia and serum factors with clinical severity. Clin Exp Allergy 1993; 23: 145-53.

[8] Kagi MK, Wutrich B, Montano E, et al. Differential cytokine profiles in peripheral blood lymphocyte supernatants and skin biopsies from patients with different forms of atopic dermatitis, psoriasis and normal individuals. Int Arch Allergy Immunol 1994; 103: 332-40

[9] Cabon N, Ducombs G, Mortureux P, Perromat M, Taieb A. Contact allergy to aeroallergens in children with atopic dermatitis: comparison with allergic contact dermatitis. Contact Dermatitis 1996; 35: 27-32.

[10] Wutrich B. Clinical aspects, epidemiology and prognosis of atopic dermatitis. Ann Allergy Asthma Immunol 1999; 83: 464-70.

[11] Schafert T, Heinrich J, Wjst M, et al. Association between severity of atopic eczema and degree of sensitization to aeroallergens in schoolchildren. J Allergy Clin Immunol 1999; 104: 1280-4

[12] Fabrizi G, Romano A, Vultaggio P, et al. Heterogeneity of atopic dermatitis defined by the immune response to inhalant and food allergens. Eur J Dermatol 1999; 9:380-4.

[13] Akdis CA, Akdis M, Simon D, et al. T cells and T cell-derived cytokines as pathogenic factors in the nonallergic form of atopic dermatitis. J Invest Dermatol 1999; 113: 628-34.

[14] Laske N, Niggemann B. Does the severity of atopic dermatitis correlate with serum IgE levels? Pediatr Allergy Immunol 2004; 15: $86-8$

[15] de Benedictis FM, Franceschini F, Hill D, et al. The allergic sensitization in infants with atopic eczema from different countries. Allergy 2009; 64: 295-303.

[16] Ricci G, Dondi A, Neri I, Ricci L, Patrizi A, Pession A. Atopic dermatitis phenotypes in childhood. Ital J Pediatr. 2014; 12; 40: 46.

[17] Leung DY, Rhodes AR, Geha RS. Enumeration of T cell subsets in atopic dermatitis using monoclonal antibodies. J Allergy Clin Immunol 1981; 67: 450-5.

[18] Leung DY. Atopic dermatitis: the skin as a window into the pathogenesis of chronic allergic diseases. J Allergy Clin Immunol 1995; 96: 302-18

[19] Kimura M, Tsuruta S, Yoshida T. Unique profile of IL-4 and IFN gamma production by peripheral blood mononuclear cells in infants with atopic dermatitis. J Allergy Clin Immunol 1998; 102: 238-44.

[20] Kimura M, Tsuruta S, Yoshida T. Correlation of house dust mitespecific lymphocyte proliferation with IL-5 production, eosinophilia, and the severity of symptoms in infants with atopic dermatitis. J Allergy Clin Immunol 1998; 101: 84-9.

[21] Spergel JM, Mizoguchi E, Brewer JP, Martin TR, Bhan AK, Geha RS. Epicutaneous sensitization with protein antigen induces localized allergic dermatitis and hyperresponsiveness to methacholine after single exposure to aerosolized antigen in mice. $\mathrm{J}$ Clin Invest 1998; 101: 1614-22.

[22] Cookson WO, Moffatt MF. The genetics of atopic dermatitis. Curr Opin Allergy Clin Immunol 2002; 2: 383-7.

[23] Palmer CN, Irvine AD, Terron-Kwiatkowski A, et al. Common loss-of-function variants of the epidermal barrier protein filaggrin are a major predisposing factor for atopic dermatitis. Nat Genet 2006; 38: 441-6.

[24] Sugawara $\mathrm{T}$, Iwamoto $\mathrm{N}$, Akashi $\mathrm{M}$, et al. Tight junction dysfunction in the stratum granulosum leads to aberrant stratum corneum barrier function in claudin-1-deficient mice. J Dermatol Sci 2013; 70: 12-8.

[25] Gschwandtner M, Mildner M, Mlitz V, et al. Histamine suppresses epidermal keratinocyte differentiation and impairs skin barrier function in a human skin model. Allergy 2013; 68: 37-47.

[26] Hennino A, Jean-Decoster C, Giordano-Labadie F, et al. CD8+ T cells are recruited early to allergen exposure sites in atopy patch test reactions in human atopic dermatitis J Allergy Clin Immunol 2011; 127: 1064-7.

[27] Kay B. Calcitonin gene-related peptide- and vascular endothelial growth factor-positive inflammatory cells in late-phase allergic skin reactions in atopic subjects. J Allergy Clin Immunol 2011; 127: 232-7.

[28] Fujita H, Shemer A, Suarez-Farinas M, et al. Lesional dendritic cells in patients with chronic atopic dermatitis and psoriasis exhibit parallel ability to activate T-cell subsets. J Allergy Clin Immunol 2011; 128: 574-82.

[29] Gros E, Petzold S, Maintz L, Bieber T, Novak N. Reduced IFN- $\gamma$ receptor expression and attenuated IFN- $\gamma$ response by dendritic cells in patients with atopic dermatitis. J Allergy Clin Immunol 2011; 128: 1015-21.

[30] Rebane A, Zimmermann M, Aab A, et al. Mechanisms of IFN- $\gamma$ induced apoptosis of human skin keratinocytes in patients with atopic dermatitis. J Allergy Clin Immunol 2012; 129: 1297-306.

[31] Zimmermann M, Koreck A, Meyer N, et al. TNF-like weak inducer of apoptosis (TWEAK) and TNF-a cooperate in the induction of keratinocyte apoptosis. J Allergy Clin Immunol 2011; 127: 200-7.

[32] Leung DY, Gao PS, Grigoryev DN, et al. Human atopic dermatitis complicated by eczema herpeticum is associated with abnormalities in IFN- $\gamma$ response. J Allergy Clin Immunol 2011; 127: 965-73.

[33] Howell MD, Gao P, Kim BE, et al. The signal transducer and activator of transcription 6 gene (STAT6) increases the propensity of patients with atopic dermatitis toward disseminated viral skin infections J Allergy Clin Immunol 2011; 128: 1006-14.

[34] De Benedetto A, Slifka MK, Rafaels NM, et al. Specificity protein 1 is pivotal in the skin's antiviral response. J Allergy ClinImmunol 2011; 127: 430-38

[35] Suárez-Fariñas M, Dhingra N, Gittler J, et al. Intrinsic atopic dermatitis shows similar TH2 and higher TH17 immune activation compared with extrinsic atopic dermatitis. J Allergy Clin Immunol 2013; 132:361-70

[36] Grewe M, Walther S, Gyufko K, Czech W, Schopf E, Krutmann J. Analysis of the cytokine pattern expressed in situ in inhalan allergen patch test reactions of atopic dermatitis patients. J Invest Dermatol 1995; 105: 407-10.

[37] Thepen T, Langeveld-Wildschut EG, Bihari IC, et al. Biphasic response against aeroallergen in atopic dermatitis showing a switch from an initial $\mathrm{TH} 2$ response to a $\mathrm{TH} 1$ response in situ: an immunocytochemical study. J Allergy Clin Immunol 1996; 97: 828-37.

[38] Gittler JK, Shemer A, Suarez-Fari nas M, et al. Progressive activation of $\mathrm{TH} 2 / \mathrm{TH} 22$ cytokines and selective epidermal proteins characterizes acute and chronic atopic dermatitis. J Allergy Clin Immunol 2012; 130: 1344-54.

[39] Eyerich S, Eyerich K, Pennino D, et al. Th22 cells represent a distinct human $\mathrm{T}$ cell subset involved in epidermal immunity and remodeling. J Clin Invest 2009; 119: 3573-85.

[40] Boniface K, Bernard FX, Garcia M, Gurney AL, Lecron JC, Morel F. IL-22 inhibits epidermal differentiation and induces proinflammatory gene expression and migration of human keratinocytes. J Immunol 2005; 174: 3695-702.

[41] Roth J, Vogl T, Sorg C, Sunderkotter C. Phagocyte-specific S100 proteins: a novel group of proinflammatory molecules. Trends Immunol 2003; 24: 155-8.

[42] Goyette J, Geczy CL. Inflammation-associated S100 proteins: new mechanisms that regulate function. Amino Acids 2011; 41: 821-42.

[43] Eckert RL, Broome AM, Ruse M, Robinson N, Ryan D, Lee K S100 proteins in the epidermis. J Invest Dermatol 2004; 123: 2333 .

[44] Bruijnzeel P, Storz E, Van Der Donk E, Bruijnzeel-Koomen C. Skin eosinophilia in patients with allergic asthma, patients with nonallergic asthma, and healthy controls. II. 20-Hydroxyleukotriene $\mathrm{B}_{4}$ is a potent in vivo and in vitro eosinophil chemotactic factor in nonallergic asthma. J Allergy Clin Immunol 1993; 91: 634-42.

[45] Wedi B, Raap U, Lewrick H, Kapp A. Delayed eosinophil programmed cell death in vitro: a common feature of inhalan allergy and extrinsic and intrinsic atopic dermatitis. J Allergy Clin Immunol 1997; 100: 536-43.

[46] Gleich GJ. Mechanisms of eosinophil-associated inflammation. J Allergy ClinImmunol 2000; 105: 651-63.

[47] Sampson AP. The role of eosinophils and neutrophils in inflammation. Clin Exp Allergy 2000; 30(s1): 22-7. 
[48] Kapp A, Werfel T. Allergic inflammation: skin. Allergy 1999; 55: 23-4.

[49] Schittek B. The antimicrobial skin barrier in patients with atopic dermatitis. Curr Probl Dermatol 2011; 41: 54-67.

[50] Nomura I, Goleva E, Howell MD, et al. Cytokine milieu of atopic dermatitis, as compared to psoriasis, skin prevents induction of innate immune response genes. J Immunol 2003; 171: 3262-9.

[51] Ong PY, Ohtake T, Brandt C, et al. Endogenous antimicrobial peptides and skin infections in atopic dermatitis. N Engl J Med 2002; 347: 1151-60

[52] Howell MD, Jones JF, Kisich KO, Streib JE, Gallo RL, Leung DY. Selective killing of vaccinia virus by LL-37: implications for eczema vaccinatum. J Immunol 2004; 172: 1763-7.

[53] Leung DY, Gao PS, Grigoryev DN, et al. Human atopic dermatitis complicated by eczema herpeticum is associated with abnormalities in IFN-g response. J Allergy Clin Immunol 2011; 127: 965-73.

[54] Kuo IH, Yoshida T, De Benedetto A, Beck LA. The cutaneous innate immune response in patients with atopic dermatitis. J Allergy Clin Immunol 2013; 131: 266-78.

[55] Sano Y, Masuda K, Tamagawa-Mineoka R, et al. Thymic stromal lymphopoietin expression is increased in the horny layer of patients with atopic dermatitis. Clin Exp Immunol 2012; 171: 330-7.

[56] Landheer J, Giovannone B, Mattson JD, et al. Epicutaneous application of house dust mite induces thymic stromal lymphopoietin in nonlesional skin of patients with atopic dermatitis. J Allergy Clin Immunol 2013; 132: 1252-4.

[57] Morita E, Takahashi H, Niihara $\mathrm{H}$ et al. Stratum corneum TARC level is a new indicator of lesional skin inflammation in atopic dermatitis. Allergy 2010; 65: 1166-72.

[58] Teraki Y, Sakurai, Izaki AS. IL-13/IL-22-coproducing T cells, a novel subset, are increased in atopic dermatitis $\mathrm{J}$ Allergy Clin Immunol 2013; 132: 971-4.

[59] Cornelissen C, Marquardt Y, Czaja K, J. et al. IL-31 regulates differentiation and filaggrin expression in human organotypic skin models. J Allergy Clin Immunol 2012; 129: 426-33.

[60] Sabat R, Grütz G, Warszawska K et al. Biology of interleukin-10. Cytokine Growth Factor Rev 2010; 21: 331-44.
[61] Boyman O, Werfel T, Cezmi A. Akdis. The suppressive role of IL10 in contact and atopic dermatitis. J Allergy Clin Immunol 2012; 129: $160-1$

[62] Oh SH, Park $\mathrm{CO}, \mathrm{Wu} \mathrm{WH}$, et al. Corticotropin releasing hormone downregulates IL10 production by adaptive forkhead box protein 3 negative regulatory $\mathrm{T}$ cells in patients with atopic dermatitis. $\mathrm{J}$ Allergy Clin Immunol. 2012; 129: 151-9.

[63] Leisten S, Oyoshi MK, Galand C, Hornick JL, Gurish MF, Geha RS. Development of skin lesions in filaggrin-deficient mice is dependent on adaptive immunity. J Allergy Clin Immunol 2013; 131: $1247-50$

[64] Esparza-Gordillo J, Schaarschmidt H, Liang L, et al. A functional IL-6 receptor (IL6R) variant is a risk factor for persistent atopic dermatitis. J Allergy Clin Immunol 2013; 132: 371-7.

[65] Kabashima K. New concept of the pathogenesis of atopic dermatitis: Interplay among barrier, allergy, and pruritus as a trinity. J Dermatol Sci 2013; 70: 3-11.

[66] Levin J, Fallon Friedlander S, Del Rosso JQ. Atopic dermatitis and the stratum corneum: part 3: the immune system. Allergy 2001; 56: 841-9.

[67] Schmid-Grendelmeier P, Simon D, Simon HU, Akdis CA, Wüthrich B. Epidemiology, clinical features, and immunology of the "intrinsic" (non-IgE-mediated) type of atopic dermatitis (constitutional dermatitis). in atopic dermatitis. J Clin Aesthet Dermatol 2013; 6: 37-44.

[68] Johansson SG, Bieber T, Dahl R, et al. Revised nomenclature for allergy for global use: report of the Nomenclature Review Committee of the World Allergy Organization, October 2003. J Allergy Clin Immunol 2004; 113: 832-6.

[69] Bieber T. Atopic dermatitis. N Engl J Med 2008; 358 :1483-94.

[70] Dondi A, Ricci L, Neri I, Ricci G, Patrizi A. The switch from nonIgE-associated to IgE-associated atopic dermatitis occurs early in life. Allergy 2013; 68: 259-60.

[71] Bieber T. Atopic dermatitis 2.0: from the clinical phenotype to the molecular taxonomy and stratified medicine. Allergy 2012; 67: $1475-82$ 